\title{
The Development of Emotional Intelligence in Children
}

\author{
Izabella Margareta KECSKES* \\ Lyceum "Samuil Micu", 547515 Sarmasu Mures, Romania \\ *)Corresponding author, e-mail: kecskesizabella@yahoo.com \\ BulletinUASVM Horticulture 72(2) / 2015 \\ Print ISSN 1843-5254, Electronic ISSN 1843-5394 \\ DOI:10.15835/buasvmcn-hort:11498
}

\begin{abstract}
Unlike cognitive intelligence, which remains unchanged during our lifetime, emotional intelligence and its parts can be grown through education and exercises. Emotional intelligence allows for a better balance in dealing with children. Exercising emotional restraint is better than allowing emotions overflow. In an attempt to develop emotional intelligence, the research used the RME emotional intelligence test followed by interventions through game play and story telling, over a period of four weeks, three times a week, totalling 12 interventions. Each intervention consisted of an aimed specific story followed by a game. At the end I conducted the RME test. The research sampled a total of 60 pupils, 28 girls and 32 boys aged 7 to11 in a three stage manner: pre-test, intervention and post-test. We identified significant differences between the initial and final stages confirming the intervention has been successful. This proves a well-designed program can develop emotional intelligence.
\end{abstract}

Keywords: Emotional Intelligence, development, performance.

\section{Introduction}

Emotional intelligence is a "form of intelligence that involves the ability of monitoring one's own emotions and feelings and that of others, facilitates discrimination between them and uses this information to control some situations or actions" (Salovey and Mayer, 1990). It is the skill of identifying and of efficient management of one's own emotions in relation to personal goals (career, family, education, etc.), the aim is to achieve one's purpose, with a minimum of interpersonal conflicts (Salovey and Mayer, 1990). Education is a highly complex and profound process. Education based on emotional intelligence starts from the fact that our action in its totality allows us to create a more healthy balance in our homes and in our relationships with children. Our actions should emphasize on the importance of our feelings and should help our children and us keep our emotions under control and not act upon the impulsive reactions. Daniel Goleman calls this theory, emotional overstimulation (Elias et al., 2007).

\section{Aims and objectives}

The purpose of this study is the importance of emotional intelligence in education and academic performance of the students. Unlike cognitive intelligence, it is not coded through life, emotional intelligence, its components, may be the most learned. Thus, the degree of emotional intelligence can be increased through education and exercises (although some components of emotional intelligence are treated as personality traits, which are harder to change).

\section{Materials and methods}

The study had a research group. We included 60 students ( 28 girls and 32 boys), aged $7-11$ years. The average age was 9 years old. We selected the students randomly from the "Samuil Micu School" in Sărmașu, $1^{\text {st }}$ grade students till $4^{\text {th }}$ grade. The 
Tab. 1. Showing the Emotional Intelligence difference between pre-test and post-test

\begin{tabular}{ccccc}
\hline \multirow{2}{*}{ Test type } & Media & Standard deviation & \multicolumn{2}{c}{ Double T test } \\
\cline { 1 - 2 } & & 3.204 & \multirow{2}{*}{10.291} & $\mathrm{p}$ \\
\hline RME pre-test & 9.933 & 3.874 & & 0.001 \\
\hline RME post-test & 12.20 & &
\end{tabular}

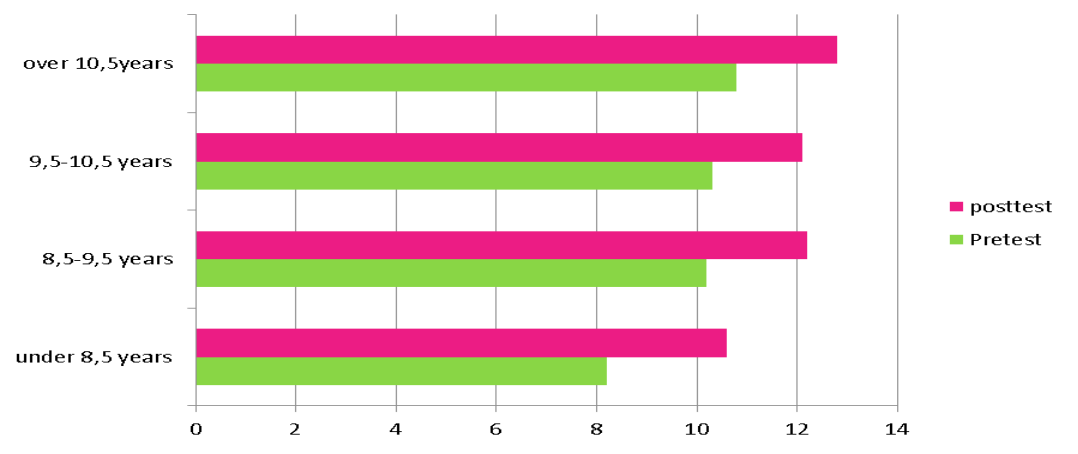

Fig. 1. Measuring emotional intelligence shown at different ages and the difference between pre-test and post-test

research was carried out in three stages: pre-test, the intervention and post-test. For this research we used the Simon Baron-Cohen and Valerie Stone test for children $(1997,2001)$, called "Reading the Mind in the Eyes", an emotional intelligence test, which contains 28 photos, with a pair of eyes on each picture. There are four possible answers. The children must circle the answer that shows most clearly what the "eyes" are thinking or feeling. Each correct answer is worth one point. High score indicates high EQ and lower score indicates a low EQ. For the intervention part we chose the game and story approach, as a way to try to develop emotional intelligence in children. There were 12 interventions, three times a week for four weeks. At every intervention we told a story which was discussed by all the participants afterwards, after which followed a game. The stories have been carefully chosen from easiest to hardest to match our purpose. After reading the stories to them we noticed that they developed many feelings like joy, love, anger, sadness, hurt, anxiety, trust, fear etc. and then we talked about the story, what happened, how they felt, to help them recognize their emotions. Each intervention was closed by different games that led to all kinds of emotions (losing, winning, happiness, anger, trust) followed by a discussion of each emotion that was felt by the children. For the post-test we repeat again the
"Reading the Mind in the Eyes" test from Simon Baron-Cohen and Valerie Stone. The conditions were the same as before.

\section{Results and discussion}

After reading stories, playing games, and discussing emotions, the kids results were much higher then at the pre-test. The intervention was very helpful as we see the significant difference between the score of the pre-test and post-test as seen in Table 1 and Figure 1.

\section{Conclusion}

Reading stories to our kids would open their minds to a lot of emotions and by talking with them about said emotions, they will be able to understand and learn how to deal with these emotions. We concluded that by playing games we can interact with them and through that they feel emotionally closer to their parents or educators, and have more trust in themselves, reducing fear and anxiety. Since the initial phase between the final differences was told, it is proof that the intervention had an effect, which shows that if we use a program properly, with it we can develop emotional intelligence. Emotional ability is very useful in raising and educating children. Parents and educators will be able to develop social and 
emotional potential in children, teaching them to adopt and develop emotional intelligence; to identify personal feelings and to differentiate them; to learn much more about how and where you can externalize their feelings; to develop empathy; to properly read the body language as well as other non-verbal and preverbal aspects, in order to understand communication, learn to listen, and learn to be constructive.

\section{References}

1. Salovey P, Mayer JD (1990). Emotional Intelligence in Imagination, Cognition and Personality, 9.

2. Elias MJ, Tobias SE, Friedlander BS (2007). Inteligența emoțională în educația copiilor, Ed. Curtea Veche, București. 